\title{
María Casares: do trasterro ó exilio
}

\author{
Maria Casares: From Emigration to Exile
}

\author{
Sabela Hermida Mondelo
}

Universidad Rey Juan Carlos

chaimae79@hotmail.com

[recibido 30/10/2014, aceptado 05/02/2015]

\section{RESUMO}

María Casares xorde como actriz universal no exilio francés, converténdose en musa da corrente existencialista e en referente para os seus compatriotas republicanos. Grazas á súa proxección artística internacional encóntrase co exilio galego en Sudamérica, chegando a converterse así nunha icona, non só artística, senón tamén política para a intelectualidade galega desterrada, na esperanza da ansiada III República.

PALABRAS CHAVE: Exilio, República, Existencialismo, Teatro, Galeguidade, María Casares..

\section{RESUMEN}

María Casares surge como actriz universal en el exilio francés, convirtiéndose en musa de la corriente existencialista y en referente para sus compatriotas republicanos. Gracias a su proyección artística internacional se encuentra con el exilio gallego en Sudamérica, llegando a convertirse así en un icono, no sólo artístico, sino también político para la intelectualidad gallega desterrada, en la esperanza de la ansiada III República.

PALABRas ClavE: Exilio, República, Existencialismo, Teatro, Galleguidad, María Casares.

\begin{abstract}
María Casares arises as an universal actress on her french exile, becoming a muse of Existentialism and a referent to her fellow republican countrymen and women. Thanks to her international artistic projection, she meets with the galician exiled in South America, thus becoming an icon, not only artistic, but political as well, for the banished galician intelligentsia, hoping for the longed-for III Republic.
\end{abstract}

KEY wORDS: Exile, Republic, Existentialism, Drama, Galicianness, María Casares.

Hermida Mondelo, S. (2015): “María Casares: do trasterro ó exilio”, Madrygal (Madr.), 18, Núm. Especial: $275-282$.

SUMARIO: 1. Da infancia en Galicia á súa etapa no Madrid da II República. 2. O exilio en Francia: actriz universal e icona da República e do existencialismo. 3. A relación con notables exiliados, galeguidade e retorno a España. 4. Referencias bibliográficas. 
1. DA INFANCIA EN GALICIA Á SÚA ETAPA NO MADRID DA II REPÚBLICA

María Victoria Casares Pérez naceu na Coruña o 21 de novembro de 1922, na residencia familiar da rúa Panaderas, actualmente convertida en "Casa-Museo Casares Quiroga". Filla de quen chegou a ser presidente do Consello de Ministros durante a II República, Santiago Casares Quiroga, e de $\mathrm{M}^{\mathrm{a}}$ Gloria Pérez Corrales, a súa primeira infancia transcorre entre A Coruña e Montovre, levando unha vida practicamente labrega, en pleno contacto coa natureza. Porén, a finais do ano 1931, María Casares sofre o trasterro a Madrid, debido ós novos compromisos políticos contraídos polo seu pai, xa que Casares Quiroga é nomeado Ministro da Marina. Esta experiencia é narrada por ela como o seu primeiro exilio emocional, pois por moito que entre 1931 e 1936 tivo unha vida verdadeiramente privilexiada, en relación á educación recibida e ó ambiente cultural no que se instala, a nena nunca chegara a acostumarse de todo á súa nova situación. "Yo soy Galicia. El primer exilio para mí fue Madrid, fue la ciudad" (Soler 1981). Presenzas habituais nos cinco anos que durou a súa estadía en Madrid foron Manuel Azaña, Juan Negrín, Rafael Alberti, Lorca, Margarita Xirgu e incluso Valle-Inclán. Con estes últimos convén destacar que desenvolve, xa na súa etapa de exiliada, unha relación a través do teatro, interpretando as súas obras ou baixo a dirección de Margarita Xirgu e Alberti. Con este último comeza unha intensa relación persoal que se mantivo ao longo da súa vida.

Nesta etapa da II República, María Casares, ademais de facer as súas primeiras incursións teatrais infantís, dótase de dúas ferramentas fundamentais para a súa evolución ética, xunto á formación recibida polos seus pais, xa que por unha parte vive o desenvolvemento do Instituto Escola ${ }^{1}$, lugar no que se inicia na música, na danza e no teatro, e ó que durante toda a súa vida non deixou de gabar como lugar de ensino, e por outra parte participa como enfermeira adolescente no Hospital Oftálmico de Madrid cando estala a Guerra Civil, onde aprende a naturalizar a morte e a dor física, así como a comprender o ser humano en toda a súa complexidade. "Con todo teño moi clara unha cousa: a estancia no hospital, a formación recibida polos meus pais e no Instituto Escola, son os tres fundamentos nos que se basea a miña vida, os que me trazaron os camiños para vivir" (Heinze 1991: 20).

Cómpre destacar que ademais do inevitable exilio para ela e a súa familia, a Guerra Civil coa ditadura franquista supón que en España se intenta minar moralmente a figura de Casares Quiroga, a quen lle chegaron a destruír a partida de nacemento no Rexistro Civil. Queimaron a súa biblioteca e todos os seus bens foron confiscados. Por outra parte, a súa irmá paterna, Esther Casares, sería encarcerada durante todo o tempo que durou a contenda e retida en España ata 1955, ano no que se exilia a México.

Ós poucos meses do estalido da Guerra Civil, María Casares, xunto a súa nai e Enrique López Tolentino, un novo miliciano da POUM (Partido Obrero de Unificación Marxista), exílianse en París, onde chegan o 20 de novembro de 1936, previo paso por Barcelona, coa axuda de Monsieur Cassamedon, alcalde dunha pedanía francesa limítrofe con España.

\section{O EXILIO EN FRANCIA: ACTRIZ UNIVERSAL E ICONA DA REPÚBLI- CA E DO EXISTENCIALISMO}

A chegada a Francia viviuna como unha época de conquistas varias, a necesidade de adaptación inminente á súa nova situación, ó idioma, á xente, ó país, polo que non tivo tempo de sentir o exilio dunha maneira inmediata. Foi

\footnotetext{
${ }^{1}$ Institución educativa española que nace o 10 de maio de 1918, en Madrid, como impulsora da reforma do ensino público e coa intención de expandir os principios pedagóxicos fundamentais da Institución Libre de Enseñanza ó ensino obrigatorio. Formaron parte na súa constitución e desenvolvemento os mellores intelectuais e científicos de España, acadando o seu máximo esplendor e madurez nos anos da II República.
} 
ó pouco da súa chegada a Francia cando se decidiu que fose actriz, en boa medida debido a súa nai, admiradora do feito teatral, e polo talento innato que viron nela o matrimonio de actores cos que entrou nunha profunda amizade, Colonna Romano, actriz da ComédieFrançais, e Alcover, actor de éxito en Francia de orixe español. Comeza os seus estudos no Conservatorio de París nos anos da ocupación nazi, o que supón unha nova fuxida para a actriz e a súa nai, xa que en 1940, ante o perigo que supuña para a familia esta situación, tiveron que esconderse, xunto a outros refuxiados, nunha vila de Burdeos, mentres Casares Quiroga tivo que trasladarse a Inglaterra con outros dirixentes republicanos, instalándose na casa de Juan Negrín, en Inglaterra. Esta nova e longa separación familiar remata en xullo de 1945, cando Casares Quiroga pode retornar a Francia. A súa formación no Conservatorio conclúe co debut teatral no Théâtre des Marthurins, cando está a punto de cumprir 20 anos, protagonizando a obra de John Millinton Synge, Deirdre des Douleurs. Esta etapa, ademais de formala e dála a coñecer coma actriz, é especialmente importante porque se vai atopar co home que, xunto ó seu pai, sería o máis importante da súa vida, Albert Camus. Aínda que coincidiran previamente nunha lectura da obra poética de Pablo Picasso, Le Désir Attrapé par la Queque, na que Camus era o encargado de dirixir o acto, oficialmente coñécense cando María Casares é elixida para protagonizar a obra do autor Le Malentendu, en 1944. Con Camus convértese en musa da corrente existencialista francesa, comezan unha intensa e prolífica colaboración profesional, ademais da súa coñecida relación sentimental, que se manterá ata a morte do premio Nobel, en 1960. Sírvanos estas palabras da actriz sobre Camus para comprender a intensidade da súa relación: "En primer lugar me dio una cosa muy importante, porque, al morir mi padre en 1950, hubo una especie de relevo, quiero decir que, en buena medida, él recogió el papel de mi padre, en el sentido afectivo, en el sentido de protección... Y sobre todo él prosiguió mi educación" (Burguet Ardiaca 1990: 38).

De Camus protagoniza, ademais de Le Malentendu, L'État de Siège, en 1948, e Les
Justes, en 1949. Alén da recoñecida influencia de Camus na vida de María Casares, todos os biógrafos do filósofo coinciden en ver na figura dela unha presenza imprescindible na vida e a obra do autor. María Casares apoiou o traballo de Camus na Resistencia, así como ambos os dous participaron en numerosos actos a favor dos exiliados españois e da conquista da democracia para España. Por outra parte, a actriz axuda o autor na adaptación de $L a D e$ voción de la Cruz, de Calderón de la Barca, y El Caballero de Olmedo, de Lope de Vega. Tamén colabora activamente na creación de Les Justes e en L'Homme Révolté.

María Casares, dende os seus comezos artísticos, convértese nun referente para os seus compatriotas republicanos exiliados, condición que lle corresponde, especialmente, por ser filla de Santiago Casares Quiroga, pero tamén por defender dende sempre o legado ético e político de seu pai, prestando a súa voz e presenza a diferentes actos organizados polos refuxiados españois na parisiense sala Pleyel durante a ocupación alemá, onde a actriz recitaba con total fervor versos de poetas españois represaliados, como Lorca, Alberti ou Machado. Tamén formou parte de diversas organizacións en defensa da República Española, como o Comité Francés de los Amigos de España, Unión de Mujeres de España, que presidía Dolores Ibarruri, ou o Comité de Ayuda a los Republicanos Españoles, presidida por Pablo Picasso.

Como recoñecemento ó mencionado compromiso concédeselle a Cruz De Gran Comendador de la Orden de Liberación por parte do Goberno da República no Exilio, medalla imposta polo propio presidente, Diego Martínez Barrio, en 1952. Ademais disto, á actriz fóronlle inculcados polos seus pais os valores de solidariedade e tolerancia, que practicou durante toda a súa vida. Boa mostra diso é que a súa casa de París foi un lugar de tránsito e acollida para os novos exiliados e para todos aqueles que o necesitaban, chegando a esconder a unha amiga xudea da persecución do réxime de Vichy. Certo é que dende moi pequena asume a responsabilidade de representar e honrar a figura do seu pai: "Fue Madrid, en efecto, donde, por primera vez, tomé conciencia de que 
tenía que "representar" - a alguien o a algo- a mi padre -la hija de un hombre de la República-, a una cierta España" (Casares 1981: 108).

Dentro de Francia coñece e relaciónase con personalidades importantísimas do mundo da cultura e da arte, estando sempre en contacto coas vangardas da época. En boa medida, polo feito de ser filla de quen era, pero tamén polo seu compromiso político e a súa calidade artística. Jean Paul Sartre, Simone de Beauvoir, Paul Claudel, Jean-Luis Barrault, Jean Cocteau, Antonin Artaud, Jean Genet, Pablo Picasso, entre outros, formaron parte da súa vida persoal e profesional. A súa crecente popularidade e recoñecemento artístico supón tamén a súa expansión como símbolo e icona política para os seus compatriotas galegos exiliados en Sudamérica, propiciada polas xiras realizadas co Théâtre National Populaire, en 1957, compañía coa que ía como primeira figura, onde a intelectualidade galega exiliada a recibiu con rotundo entusiasmo e recoñecemento artístico. No teatro Cervantes de Bos Aires esperábana personaxes tan importantes como Blanco Amor, Ramón de Valenzuela, Luís Seoane, Laxeiro, Rafael Dieste, Rei Baltar ou o actor Fernando Iglesias "Tacholas".

Para exemplificar a calidade e a trascendencia artística acadada por María Casares, sírvannos estas significativas e emotivas verbas que lle adica Jorge Lavelli, un dos directores máis relevantes e importantes para ela, non só no ámbito profesional, senón tamén no persoal e no humano:

Maria n'est pas une comédienne comme les autres. C'est une personnalité hors pair. Elle apporte avec elle tout un univers qui dépasse le travail ordinaire de l'acteur. En parlant d'elle, Jean Vilar disait qu'elle était «un pilier de sa troupe», c'est-à-dire un personnage qui déborde d'une extraordinaire énergie positive canalisée dans le travail. Cette énergie est contagieuse. Avoir Maria dans une compagnie, c'est une chance hors du commun. Tout le monde est stimulé par son travail. Je ne connais aucun autre comédien capable d'une telle concentration...

La subtilité avec laquelle elle travaille, l'intelligence du regard qu'elle peut jeter sur un personnage, renforcent le côté stimulant de sa présence. Elle ne triche jamais. Toute sa sensibilité et toute son énergie passent dans ce qu'elle fait, avec la même «impudeur» que celle d'un écrivain. C'est pourquoi son jeu me paraît d'une nature rarement trouvée dans le Théâtre, d'une certaine manière déjà proche de l'écriture. (Lavelli 1980)

\section{A RELACIÓN CON NOTABLES EXI- LIADOS, GALEGUIDADE E RETOR- NO A ESPAÑA}

A partir de este momento Seoane dedícalle numerosos textos e audicións na revista $G a$ licia Emigrante e no homónimo programa de radio, entre 1954 e 1971. Para Luís Seoane, María Casares convértese nun punto de referencia por unha dobre motivación: a persoal, que son os sólidos principios éticos da actriz a favor da liberdade e da democracia, así como o seu amor e recoñecemento pola súa Galicia natal, e a artística, xa que puido comprobar o seu talento interpretativo en varias ocasións, de modo moi especial no seu papel de MariGaila, de Divinas Palabras, que se representou no Teatro Coliseo de Bos Aires en 1964. Para resumir o que a actriz supuxo para Luís Seoane extraemos o seguinte fragmento:

María Casares es para nosotros algo más que la genial intérprete de la escena, continuadora, por sí así la quieren los críticos franceses, de Sarah Bernhardt: es la bandera de ese pueblo exiliado, de dignidad, de amor a la libertad, de justicia, como lo son Pablo Picasso y Pablo Casals, y lo fueron Castelao y Companys. (Braxe e Seoane 1996: 57).

Outro exemplo da transcendencia conseguida pola actriz para os seus compatriotas galegos é que en outubro de 1957 foi homenaxeada na cidade de Bos Aires polo Concello de Galicia, esque estaba integrado, entre outros, por Ramón Suárez Picallo, quen lle dedica unhas verbas que mostran suma admiración e recoñecemento por ela. Tamén consta o seu encontro, no mesmo ano, coa viúva de Castelao, Virxiña Pereira, a través dunha das cartas que lle envía esta á familia de Otero Pedrayo dando noticia deste acontecemento con intensa emotividade e deixando constancia da súa admiración pola actriz, á que afectivamente denomina co hipocorístico de Maruxa: 
A emoción que Maruxa Casares e máis eu sentimos co noso encontro foi algo difícil de se espricar. A primeira visita da súa chegada a Bos Aires foi pra min, e bicándome i abrazándome forte non atinaba a me decir palabra. Eu tampouco. Pasando o primeiro intre, descobrín con ledicia que é simpática, intelixente e sinxela como todol-os que valen. Foi así como me gañou, facéndome saír das miñas "casillas" asistindo a unha comida que lle ofreceron os galeguistas, e ¡PASMAROS...! a vela actuar no teatro Colón, onde a nosa Maruxa estivo formidable en María Tudor. (Alonso Montero 2012: 149)

En Sudamérica continuaron os eloxios á súa figura ó longo da súa vida. Outra mostra diso é que dende Bos Aires, en setembro de 1987, La Opinión Gallega considerábaa como a maior honra de Galicia no estranxeiro, equiparándoa en importancia con Rosalía de Castro, Concepción Arenal ou a Pardo Bazán.

A súa condición de galega defendeuna sempre con total rotundidade. Entre os seus referentes poéticos encontrábanse Rosalía de Castro e Curros Enríquez. Deste último recitou o seu poema "Saúdo" no mencionado programa de radio Galicia Emigrante, no ano 1957, cunha perfecta dicción galega e cunha emoción tal que as bágoas lle impediron rematar. Tamén todos os días da patria galega, a modo de homenaxe á súa terra, recitaba versos de autores galegos pola radio francesa. No plano afectivo, María Casares mantivo un recordo idílico e fotográfico na súa memoria da súa Galicia natal, ata o punto de non querer voltar por temor a decepcionarse. Mostra deste recoñecemento podémolo ver nas palabras que dedica ós galegos emigrados, nunha entrevista que lle concedeu a Víctor Luis Molinari en 1957, sabedora da esperanza que ela representaba, "porque vivimos en función de futuro. Y el futuro es sólo nuestro. Solo nuestro. En este futuro yo me veo en Galicia, por los caminos de Galicia, representando para mi pueblo y dándole a él lo mejor de mi espíritu" (Molinari 1957: 12).

Por último, nunca perdeu, nin quixo perdelo, o seu marcado acento galego. De feito, en Francia nunca supuxo un problema, mentres que en España se mostrou sorprendida e decepcionada cando se intentou atenuar para a súa participación no Adefesio. De tódalas maneiras, sen perder este sentimento de singularidade e identidade galega que ela mesma expón da seguinte maneira: "Galicia soy yo. Galicia no soy yo, pero yo soy Galicia, un trocito de Galicia" (Soler 1981), universalízase a través da creación e da experiencia do exilio. Sírvanos para demostralo esta concisa e simbólica frase: "El teatro es mi patria" (Casares 1981: 341).

En canto á súa relación con outros exiliados españois, cabe destacar a mantida con Margarita Xirgu e Rafael Alberti. O seu contacto con Margarita Xirgu, á parte da súa época infantil na que puido comprobar o seu talento interpretativo en Yerma, en Madrid, durante a II República, remóntase ó ano 1956, cando se cumprían os vinte anos do asasinato de García Lorca. Nesta ocasión a actriz escribe a Margarita Xirgu para comunicarlle que se vai organizar unha homenaxe ó dramaturgo no que participarían, entre outros, Picasso e Carmen Pitoëff. Tamén lle mostra o seu desexo de levar a cabo un proxecto teatral, o da La Casa de Bernarda Alba, que quería que fose dirixido e protagonizado pola propia Margarita, a modo de recoñecemento, non só ó poeta granadino, senón tamén á actriz que o revelou. Posteriormente chegou o encontro coa súa admirada Margarita, en 1963, xa que é dirixida por ela en Yerma, estreada o 29 de maio no Teatro Municipal General San Martín, en Bos Aires. Foi ela mesma quen decidiu ser dirixida por Xirgu, xa que o paso dos anos non fixo máis que incrementar a súa admiración por ela, tanto a nivel teatral, como polo carácter liberal da súa personalidade. Esta experiencia non chegou a satisfacer de todo á actriz, xa que confesaba non ter a sensación de encontrar a Lorca, talvez por ser a primeira vez que interpretaba en castelán, ou por certa indiferenza da propia Margarita Xirgu, quizais desmotivada pola idade, xa que daquela contaba con 75 anos. Durante a vida de Margarita Xirgu, María Casares era informada da evolución artística da actriz no desterro, a través da correspondencia que mantiña con Alberti.

En canto á súa decisión de retornar a España, tivo claro dende o principio que lle gustaría que fose a partir de todo o que representaba a 
súa vida, isto é, do teatro. Por iso, cando Alberti propón que participe no Adefesio, encontra o momento e a maneira idónea para voltar, encontrando nel o vínculo posibilitador para o seu retorno a España:

Por eso, la propuesta de hacer el Adefesio me llegó como una salvación. Antes me habían propuesto otras cosas, que rechacé; pero esta vez, por lo que representaba Alberti en todos los sentidos, por lo que representa su obra, y porque ésta me gusta muchísimo, tenía la oportunidad de volver a España. Eso nunca lo olvidaré, ni podré agradecérselo bastante a Alberti. (Monleón 1990: 415)

Este proxecto, máis que pola dimensión artística que lle achegaba á súa dilatada carreira, foi importantísima pola significación persoal que lle supoñía, xa que coa interpretación de "Gorgo" se produce o seu retorno a España, poñendo fin a 40 anos de exilio, o que constitúe, segundo as súas propias palabras, o peche do seu principal ciclo vital, precisamente nun momento no que lle foi negada a entrada ó propio Alberti. De tódalas maneiras non foi esta unha experiencia de todo satisfactoria, xa que ademais dunha enfermidade durante a xira realizada, o seu recibimento non foi acorde nin co seu nivel como actriz nin coa súa calidade humana. Ela mesma resume estes sentimentos encontrados:

En cuanto a la España objetiva la encuentro borracha. Abren unas ventanas y la gente se precipita por esas ventanitas. Hay un desgaste total de energía ya en el hablar. Es increíble lo que se habla en este país. Se habla a gritos y uno se pregunta si queda un poco de energía para hacer. Por otro lado, los españoles son cálidos y naturales. Estoy partida en dos, entre la ternura (porque se notan tanto los 40 años de ahogo y castración) y el enfado. (Casares 1977: 67)

Tamén é certo que para moitos españois republicanos se converteu nun mito do exilio republicano, como podemos comprobar a través destas verbas de Manuel Aznar Soler:
Definitivamente, María Casares -a quien, sin embargo, en octubre de 1991 había podido contemplar en el Mercat de les Flors de Barcelona como Doña María de las Comedias Bárbaras, la trilogía trágica del genial dramaturgo gallego Valle-Inclán-, iba a convertirse para siempre en mi imaginario escénico, junto a Margarita Xirgu, en un mito de nuestro exilio teatral republicano de 1939. (2006: 1075)

Debemos recordar que a súa relación con Alberti se inicia moitos anos antes. Mostra da importancia desta relación pode comprobarse na entrevista concedida a José Monleón (1990), recollida en Tiempo y Teatro de Rafael Alberti, na que se expón a clara intimidade que chegaron a acadar o escritor e a actriz. No Instituto Escola foi dirixida por el na obra El príncipe que todo lo aprendió en los libros, de Jacinto Benavente. No ano 1945, dende o exilio mutuo, comezan unha correspondencia, a través da cal o autor a felicita polos éxitos alcanzados, mostrando o seu respecto e admiración pola actriz, coa esperanza de que algún día represente algunha das súas obras. En canto á alegría que supuxo para Alberti que a actriz aceptase interpretar a "Gorgo", extráese a seguir un fragmento da carta enviada polo poeta a María Casares con motivo da estrea do Adefesio:

La pena inmensa de los años de pérdida, del desarraigo, y del peregrinar para nosotros españoles del exilio, y la inmensa alegría de comprobar una vez más, que el dolor y en tierras lejanas puede surgir una flor maravillosa y trágica, que aún en otra lengua se alimentó siempre con la savia de su pueblo. Esa eres tú, María; tu presencia en la escena española será como un fuerte viento purificador ${ }^{2}$.

Despois deste final como exiliada, xa no seu retorno a Francia, é de destacar que escribe a súa valorada autobiografía Residente Privilegiada, na que se mostra unha fiable perspectiva da súa existencia. Nace como a necesidade de ordenar as súas ideas e os seus sentimentos,

\footnotetext{
${ }^{2}$ Epístola manuscrita do 25 de setembro de 1976, arquivada nos “Fondos María Casares", da Biblioteca Nacional Francesa.
} 
como unha busca existencial das súas raíces e identidade, impulsada por esta experiencia do fin do exilio e o retorno á patria.

María Casares mantivo sempre a súa condición de exilada. De feito, aínda que tivo ocasión de se converter en cidadá francesa, nunca quixo renunciar a ser como os demais refuxiados ata que se acabase a ditadura franquista. A súa aceptación da nacionalidade francesa foi posterior e simbólica, en agradecemento ó país que a acolleu, mediante o seu matrimonio con André Schlesser. A súa experiencia do exilio provocou na actriz un sentimento de desasosego e angustia vital que marcou a súa vida, e que ela resume da mellor maneira posible na seguinte frase "Desde que abandoné España en el año 1936, siempre he vivido en estado de urgencia" (Casares 1981: 105).

Francia outorgoulle unha transcendencia artística de tal magnitude que a converteu nunha das máis aclamadas actrices tráxicas contemporáneas. Proba da súa calidade artística son os premios obtidos ó longo da súa carreira, destacando sobre todos eles a Lexión de Honor Francesa e o Premio Nacional de Teatro francés, que lle foron concedidos en 1990, ou a Medalla al Mérito de las Bellas Artes Española, outorgada no ano 1988. Na súa terra natal, os recoñecementos comezan no ano 1984, cando o concello da Coruña a nomea "Filla Predilecta" da cidade. Ademais, a Xunta de Galicia outórgalle no ano 1990 a Medalla Castelao. Non obstante, considero que a mellor homenaxe, para unha muller que dedicou toda unha vida ó teatro, é o feito de que os premios que concede cada ano a Asociación de Actores e Actrices de Galicia ás artes escénicas, dende 1997, se denominen "Premios María Casares". Segundo nos conta Lino Braxe, esta honra aceptouna mediante conversa telefónica.

O que xa nunca saberemos é se aceptaría a invitación á cerimonia da primeira edición, xa que pouco antes, o 22 de Novembro de 1996, falecía en Alloue, no distrito francés de Confolen. Pero tódolos éxitos alcanzados e tódalas súas experiencias vitais nunca chegaron a borrar o seu sentimento de desterro: "Creo que cuando uno está exiliado una vez, está exiliado para siempre, pero también se aprende otra cosa, que no hay fronteras" (Soler 1981).

\section{REFERENCIAS BIBLIOGRÁFICAS}

Alonso Montero, Xesús (2012): "Seis cartas (tres inéditas) de Virxiña Pereira Rende (de Castelao) á familia de R. Otero Pedrayo", A Estrada (Miscelanea Histórica e Cultural) 15, pp. 127-150.

Aznar Soler, Manuel (2006): Escritores, y Revistas del Exilio Republicano de 1939. Sevilla: Biblioteca del Exilio / Editorial Renacimiento.

Braxe, Lino e Xavier Seoane (1989): Escolma de Textos de Audición Radial de Luís Seoane, Galicia Emigrante (1954-1971). Sada: Ediciós do Castro.

(1996): Luís Seoane e o Teatro. Sada: Ediciós do Castro.

Burguet Ardiaca, Francesc (1990): Protagonistas. Trece entrevistas con el mundo del teatro y un epílogo con Federico García Lorca. Barcelona: Ultramar Ediciones.

CAsares, María (1977): “El Teatro como Exorcismo”, Revista Bazaar, p. 67.

(1981): Residente Privilegiada (trads. F. García-Prieto Buendía e E. Sordo). Barcelona: Argos Vergara.

Heinze, Úrsula (1991): Mulleres. Vigo: Xerais.

MolinARI, Víctor Luis (1957): "María Casares, gallega y actriz universal”, Galicia Emigrante 31, pp. 11-15.

LaVELLI, Jorge (1980): “Maria L'Impudique”, Le Quotidien de Paris 15/02/1980. 
Monleón, José (1990): Tiempo y Teatro de Rafael Alberti. Madrid: Primer Acto / Fundación Rafael Alberti.

Pérez Lorenzo, Manuel, Francisco A. Pita Fernández, Emilia García López e Prudencio Viveiro Mogo (2008): Ramón Suárez Picallo. Escolma de Textos en Galego. Sada / Santiago de Compostela: Concello de Sada / Consello da Cultura Galega.

Soler, Joaquín (1981): "María Casares", entrevista en A Fondo, TVE1. 